\title{
Epistaxis: Management Protocol As Per Etiology
}

\section{${ }^{1}$ Anish K Gupta, ${ }^{2}$ Sandip Jain, ${ }^{3}$ Devinder Pal Singh, ${ }^{4}$ Ashwani Jindal, ${ }^{5}$ Kuldeep Singh}

${ }^{1}$ Senior Consultant, Department of ENT, Head and Neck Surgery, Fortis Hospital, Mohali, Punjab, India

${ }^{2}$ Senior Consultant, Department of Pediatrics, Fortis Hospital, Mohali, Punjab, India

${ }^{3,4}$ Consultant Emergency Medicine, Fortis Hospital, Mohali, Punjab, India

${ }^{5}$ Chief, Transfusion Medicine, Fortis Hospital, Mohali, Punjab, India

Correspondence: Anish K Gupta, Senior Consultant, Department of ENT, Head and Neck Surgery, Fortis Hospital, Mohali Punjab, India, e-mail: anishpgi123@gmail.com

\begin{abstract}
Aim: To underline a management protocol for epistaxis as per etiology so as to reduce associated morbidity of repeated packing, procedures and hospitalization.

Materials and methods: This was a prospective study carried out over a period of 2 years from January 2007 till December 2008 wherein all the cases that presented with a symptom of acute epistaxis to the emergency department of Fortis Hospital, Mohali were, enrolled into the study. These cases were evaluated for the brief history (a detailed history was taken after the primary management in majority of the cases), physical examination, diagnostic nasal endoscopy, radiology (if needed), hematological and biochemical profile and cross match (if needed). All these patients were hospitalized and were grouped into two groups on the basis of the age with group A having cases under 14 years of age and group B having cases more than 14 years of age. These cases were managed by a definitive management protocol stated in detail. Following this protocol for the management, we studied the duration of hospitalization for it and the frequency of repeated packing that patient had to undergo.

Results: A total of 97 cases were studied in this study with 26 cases in group A and 71 cases in group B. There was a male predominance with 20 males in group $A$ and 52 males in group B. The most common etiology in group A was decrease in platelet count secondary to ITP (Idiopathic thrombocytopenic purpura) and in group B was accelerated hypertension. There was only anterior bleeding in only 10 of these cases and 81 cases had anterior and posterior bleeding. The cases were managed as per etiology following a management protocol and by this we could reduce hospitalization as in highlighted in the tables.

Discussion: There is no defined management protocol for the management of epistaxis as per the etiology though there are many studies on different treatment options used and its results. We here could follow a management protocol for different etiologies.

Conclusion: The management protocol as per etiology for hypertension if used can reduce the hospitalization and also associated morbidity of repeated packing considerably.
\end{abstract}

Keywords: Epistaxis, management, protocol, hypertension.

\section{INTRODUCTION}

Epistaxis is a common disorder, with most people having experienced 1 or more episodes in their lifetime. Some estimates suggest that as many as $60 \%$ of the population may have suffered from epistaxis at some point in their lifetime. ${ }^{1,2}$ Epistaxis occurs in persons of all ages, seen more often in males in older age groups. Epistaxis also occurs more frequently in dry environments such as in the desert or in the winter in the cooler climates, where, the lack of humidity dries the mucosa of the anterior nasal septum. ${ }^{2}$ Most often, these nosebleeds tend to be minor and are relatively easily managed with pressure or stop spontaneously.

On occasion, however, epistaxis can be quite difficult to manage. This is particularly true in patients who have hypertension, are on blood thinners or aspirin, or have a familial history of a bleeding disorder such as hemophilia. Such cases may require management by an emergency room physician or otolaryngologist. The primary management is typically through cautery, nasal packing, or endoscopicguided selective cauterization. On rare occasions, more extensive bleeds may require surgical management with endoscopic control or vessel ligation. Patients who cannot otherwise be managed will occasionally be managed with angiography with embolization. ${ }^{3-8}$ Fortunately, the more common episodes are self-limited or require less invasive management. Current available data suggests that only approximately $10 \%$ of patients seek medical attention for nosebleeds. Within this group, only a small percentage require consultation with an otolaryngologist to control the bleeding, suggesting that otolaryngologists see only 0.5 to $1 \%$ of the total population who experience nosebleeds. 
It can have varied etiology. It results in significant morbidity and rarely even mortality. There have been many articles published about its various aspects. ${ }^{4-7}$ There is no single article that addresses the issues of management protocol as per the etiology for epistaxis. We here report our experience in a setting of tertiary care hospital about the etiology, management aspects of this entity and propose a management protocol on the basis of etiology that can help in reducing the agony of repeated packing and decrease the duration of hospitalization.

\section{MATERIALS AND METHODS}

This was a prospective study carried out over a period of 2 years from January 2007 till December 2008 wherein all the cases that presented with a symptom of acute epistaxis to the Emergency Department of Fortis Hospital, Mohali were, enrolled into the study. These cases were evaluated for the brief history (a detailed history was taken after the primary management in majority of the cases), physical examination, diagnostic nasal endoscopy, radiology (if needed), hematological and biochemical profile and cross match (if needed). All these patients were, hospitalized and were grouped into two groups on the basis of the age with group A having cases under 14 years of age and group B having cases more than 14 years of age. The cases in which local examination showed a bleeding area or spot were taken up for cauterization of the lesion and packing of the nose with gelfoam (Management Option 1). The cases where, the site could not be localized either due to poor cooperation by the patient or cases with severe bleeding were managed with anterior nasal packing initially (Management Option 2). If it did not result in cessation of bleeding, posterior nasal packing was done using foley's catheter with the balloon placed in the nasopharynx and inflated with up to 20 cc of air (Management Option 3). The cases which still did not stop bleeding or had bleeding again after the pack removal (done 3 days after the packing) were taken up for digital substraction angiography (DSA) for the ethmoidal arteries and the sphenopalatine artery and underwent either anterior ethmoidal or sphenopalatine artery coagulation depending upon the vessel involved (Management Option 4). In cases with mass lesion in the nasal cavity, the mass lesion was removed under general anesthesia (Management Option 5). The coagulation profile and the platelet count was corrected. Blood pressure was brought under control in cases with hypertension. Following this protocol for the management, we studied the duration of hospitalization for it and the frequency of repeated packing that patient had to undergo.

\section{RESULTS}

There were 97 cases in the study with 26 cases in group A and 71 cases in group B. The age ranged from 3 months to 78 years. The mean age in group A was 6 years and in group B was 59 years. There was a male predominance with 20 males in group A and 52 males in group B. The most common etiology in group A was decrease in platelet count secondary to ITP (Idiopathic thrombocytopenic purpura) and in group B was accelerated hypertension. The etiology of both the groups is summarized in Table 1. There was only anterior bleeding in only 10 of these cases and 81 cases had anterior and posterior bleeding. All the cases of nose picking were managed successfully with cauterization alone. The cases of trauma without associated nasal deformity or with minimal deformity were managed with cauterization. The cases with marked nasal deformity that had persistent bleeding were taken up for DSA showing bleeding to be from anterior ethmoidal artery and these were managed with endoscopic endonasal vessel coagulation. The patients with nasal mass lesion or with adenoid hyperplasia were managed with surgical removal of the lesion. The mass lesion in both the adults was in males and was inverted papilloma on histological examination. The patients with thrombocytopenia or those that were on blood thinners were managed with anterior nasal packing alone. The patients with impaired coagulation profile were managed either with anterior packing or posterior packing. The cases with hypertension were managed with posterior nasal packing but in a few it required endoscopic endonasal sphenopalatine artery coagulation as was seen on DSA. The management options used are summarized in Table 2. The management option that was successfully used for both the groups are summarized in Table 3. Most common management option used was option 2 in group A and option 3 in group B. Table 4 summarizes the management option used in different etiologies. None of the cases managed required repacking.

Table 1: Etiology of epistaxis in the groups

$\begin{array}{lrr}\text { Etiology } & \begin{array}{r}\text { Number of cases } \\ \text { (Group A) }\end{array} & \begin{array}{r}\text { Number of cases } \\ \text { (Group B) }\end{array} \\ \text { Nose picking } & 4(15.4 \%) & 5(7.04 \%) \\ \text { Trauma } & 7(26.9 \%) & 12(16.9 \%) \\ \text { Nasal mass lesion } & - & 2(2.8 \%) \\ \text { Adenoiditis } & 2(7.68 \%) & - \\ \text { Hypertension } & - & 30(42.3 \%) \\ \text { Impaired coagulation profile } & - & 5(7.04 \%) \\ \text { Decrease in platelet count } & 13(50 \%) & 10(14.08 \%) \\ \text { Blood thinners } & - & 7(9.86 \%) \\ \text { Hemophilia } & - & -\end{array}$


Table 2: Management options used

\section{Management option}

Option 1

Option 2

Option 3

Option 4

Option 5
Cauterization

Anterior nasal packing

Posterior packing or tamponade

Vessel ligation

Removal of the mass lesion
Table 3: Management options used for the groups

$\begin{array}{lcc}\begin{array}{l}\text { Management } \\ \text { option }\end{array} & \begin{array}{c}\text { Number of cases } \\ \text { (Group A) }\end{array} & \begin{array}{c}\text { Number of cases } \\ \text { (Group B) }\end{array} \\ \text { Option 1 } & 8 & 11 \\ \text { Option 2 } & 13 & 16 \\ \text { Option 3 } & - & 28 \\ \text { Option 4 } & 3 & 11 \\ \text { Option 5 } & 2 & 2\end{array}$

Table 4: Successful management option as per etiology

$\begin{array}{lrrrcc} & \text { Option } & \text { Option } & \text { Option } & \text { Option } & \text { Option } \\ & 1 & 2 & 3 & 4 & 5 \\ \text { Nose picking } & 9 & - & - & - & - \\ \text { Trauma } & 10 & - & - & 9 & - \\ \text { Mass lesion } & - & - & - & - & 2 \\ \text { Adenoiditis } & - & - & - & - & 2 \\ \text { Hypertension } & - & - & 25 & 5 & - \\ \begin{array}{l}\text { Impaired } \\ \text { coagulation }\end{array} & - & 2 & 3 & - & - \\ \text { profile } & & & & & \\ \text { Decrease in } & - & 23 & - & - & - \\ \text { platelet count } & & & & & - \\ \text { Blood thinners } & - & 7 & - & - & -\end{array}$

Table 5: Impact of the protocol on repacking and duration of hospitalization

\begin{tabular}{|c|c|c|}
\hline & $\begin{array}{c}\text { Requiring revision } \\
\text { packing }\end{array}$ & $\begin{array}{r}\text { Duration of } \\
\text { hospitalization }\end{array}$ \\
\hline Option 1 & - & 1 day \\
\hline Option 2 & - & 2 days \\
\hline Option 3 & - & 4 days \\
\hline Option 4 & - & 6 days \\
\hline Option 5 & - & 3 days \\
\hline
\end{tabular}

The hospitalization required varied from 1 to 6 days. Following this management protocol, we could reduce the incidence of repeated packing and duration of hospitalization (Table 5).

\section{DISCUSSION}

Epistaxis or nose bleed can be horrifying for the patient and at times for the treating physician. It is more common in the older age group and has diverse etiology. The most common etiology is nose picking in children and hypertension in elderly whereas in adolescence and early adulthood it is trauma as was seen in our series. ${ }^{1-3} \mathrm{We}$, in our series noted it to be more common in older age group and is in concordance with the literature. ${ }^{3}$

The management options can be cauterization (electric or chemical), packing, posterior tamponade, vessel ligation (endoscopic or external approach) or embolization. There is no article that states the ideal management protocol for epistaxis as per etiology. We here studied the role of different management options for different etiological reasons for epistaxis and found that following a definitive management protocol for this entity can reduce the duration of hospitalization and agony of repeated packing.

For cases with nose picking as the only etiology, cauterization of the culprit area is the best option and has been shown to be safe and reduces hospitalization to almost less than a day. ${ }^{4-7}$

For cases with trauma as an etiology, we observed that if there is a significant nasal deformity, there are high chances of anterior ethmoidal artery to be the culprit vessel responsible for epistaxis. It was seen in all of our cases that had marked deviation of nasal dorsum and associated naso ethmoid fractures. These cases required anterior ethmoidal artery ligation that was done endoscopically in our series. Hence, the cases that have significant deformation of the dorsum with epistaxis should be evaluated with DSA to rule out arterial bleeding as an etiology. ${ }^{8}$ Literature does not mention such corollary.

For cases with mass lesions in the nose or nasopharynx, it is best to remove such lesions as it cures epistaxis and this was the dictum followed by us in our study.

For cases with decreased platelet count and those on blood thinners, the option that we followed and worked for all the cases was anterior packing and no posterior tamponade was needed for such cases. Pack was usually removed on the third day and corrective measures in relation to etiology were taken out.

Hypertensive nose bleeds is one of the most dreaded and difficult bleeds to manage and there are a number of different options that have been used for the management of it. It not only requires packing but also reduction of the blood pressure to the normal level that too not at a very fast pace as that can result in cardiac ischemia. Moreover such bleeds are posterior and are severe and are mostly managed with posterior packing or tamponade as was seen in our series as well. ${ }^{9-14} \mathrm{~A}$ few do require DSA and vessel ligation but of the sphenopalatine vasculature and was needed in $17 \%$ of our cases as well. ${ }^{15-19}$

So we here summarize that all cases of epistaxis should be managed aggressively to reduce the hospitalization time and associated morbidity and by following the above mentioned protocol we could reduce it. 


\section{REFERENCES}

1. Juselius H. Epistaxis: A clinical study of 1724 patients. J Laryngol Otol 1974;88:317-27.

2. Petruson B. Epistaxis: Clinical study with special reference to fibrinolysis. Acta Otolaryngol (Stockh) 1974;317:3-73.

3. Small M, Murray JAM, Maran AGD. A study of patients with epistaxis requiring admission to hospital. Health Bull (Edinb) 1982;40:20-29.

4. Rubin J, Rood S, Myers E, Johnson J. The management of epistaxis. Self-instructional package. Alexandria, Va.: American Academy of Otolaryngology-Head and Neck Surgery 1990.

5. Schaitkin B, Strauss M, Houck JR. Epistaxis: Medical versus surgical therapy: A comparison of efficacy, complications, and economic considerations. Laryngoscope 1987;97:1392-96.

6. Shaw CB, Wax MK, Wetmore SJ. Epistaxis: Comparison of treatment. Otolaryngol Head Neck Surg 1993;109:60-65.

7. Monux A, Tomas M, Kaiser C, et al. Conservative management of epistaxis. J Laryngol Otol 1997;104:868-70.

8. Sokoloff J, Wickbom I, McDonald D, Brahme F, Goergen TG, Goldberger LE. Therapeutic percutaneous embolization in intractable epistaxis. Radiology 1974;111:285-87.

9. Wang L, Vogel DH. Posterior epistaxis: Comparison of treatment. Otolaryngol Head Neck Surg 1981;89:1001-06.

10. McFerran DJ, Edmonds SE: The use of balloon catheters in the treatment of epistaxis. J Laryngol Otol 1993;107:197.
11. Frikart L, Agrifoglio A. Endoscopic treatment of posterior epistaxis. Rhinology 1998;36:59-61.

12. Elwany S, Abdel-Fatah H. Endoscopic control of posterior epistaxis. J Laryngol Otol 1996;110:423-34.

13. Bingham B, Dingle AF. Endoscopic management of severe epistaxis. J Otolaryngol 1991;20:6-7.

14. Cannon CR. Effective treatment protocol for posterior epistaxis: A 10-year experience. Otolaryngol Head Neck Surg 1993;109:722-25.

15. Wurman LH, Sack JG, Flannery JV. The treatment of posterior epistaxis by internal maxillary artery ligation or endoscopic posterior nasal electrocautery. Presented at the Annual Meeting of the American Academy of Otolaryngology-Head and Neck Surgery, Washington DC Sept 1988;25-29.

16. Lee H, Kim H, Kim S, et al. Surgical anatomy of the sphenopalatine artery in lateral nasal wall. Laryngoscope 2002;112:1813-18.

17. Babin E, Moreau S, Goullet de Ruby M, et al: Anatomic variations of the arteries of the nasal fossa. Otolaryngol Head Neck Surg 2003;128:236-39.

18. Hunter K, Gibson R. Arterial ligation for severe epistaxis: Survey of 60 cases. Laryngoscope 1973;83:517-25.

19. Simpson GT, Janfaza P, Becker GD. Transantral sphenopalatine artery ligation. Laryngoscope 1982;92:1001-05. 